\title{
Analyses and Interpretation of Ground Magnetic Data at Sungai Batu, Kedah, Malaysia in Search for Buried Archaeological Remains
}

Sabiu Bala Muhammad, ${ }^{1,2 *}$ Rosli Saad, ${ }^{1}$ Mokhtar Saidin, ${ }^{3}$ Mustapha Adejo Mohammed,,${ }^{1,4}$ Yusuf Abubakar Sanusi, ${ }^{1}$ Yakubu Mingyi Samuel, ${ }^{5}$ Rais Yusoh ${ }^{1}$ and Sirajo Abubakar ${ }^{6}$

${ }^{1}$ Geophysics Section, School of Physics, Universiti Sains Malaysia, 11800 USM Pulau Pinang, Malaysia

${ }^{2}$ Department of Physics, Usmanu Danfodiyo University, P.M.B. 2346 Sokoto, Nigeria

${ }^{3}$ Centre for Global Archaeological Research, Universiti Sains Malaysia, 11800 USM Pulau Pinang, Malaysia

${ }^{4}$ Department of Physics, Federal University, P.M.B. 146 Lafia, Nigeria

${ }^{5}$ School of Science and Technology, Federal Polytechnic, P.M.B. 1006 Damaturu, Yobe State, Nigeria

${ }^{6}$ Department of Physics, Sokoto State University, P.M.B. 2134 Sokoto, Nigeria

*Corresponding author: sabiubala@gmail.com

Published online: 25 August 2020

To cite this article: Muhammad, S. B. et al. (2020). Analyses and interpretation of ground magnetic data at Sungai Batu, Kedah, Malaysia in search for buried archaeological remains. J. Phys. Sci., 31(2), 33-43. https://doi.org/10.21315/jps2020.31.2.3

To link to this article: https://doi.org/10.21315/jps2020.31.2.3

\begin{abstract}
Ground magnetic data were acquired, analysed and interpreted for shallow archaeological investigation at Sungai Batu, Lembah Bujang, Kedah, Malaysia. The objective is to locate buried archaeological remains, typically in form of baked clay bricks in the surveyed area. Magnetic field intensity data were acquired using G-856 proton type magnetometer at $1 \mathrm{~m}$ by $2 \mathrm{~m}$ grid spacing. During the data acquisition, suitable base station was established $50 \mathrm{~m}$ away from the study area, to take readings at 1-min interval for diurnal data correction and regional-residual separation. Residual field intensity values obtained were in the range of $-25 n T$ to $177 n T$. The values were generally divided into two main classes: low magnetic $(<38 n T)$, and high magnetic $(>38 n T)$. The data were gridded and contoured using Oasis Montaj software to obtain the magnetic residual field intensity map. The gridded data were reduced to magnetic equator to shift peaks of anomaly over centres of magnetic source. Automatic gain control filter was thereafter applied to enhance signal in regions of low field variation and to suppress signal in regions with high field variation. The process revealed sharp anomalies interpreted as signatures of baked clay bricks at the western and eastern parts of the area.
\end{abstract}

Keywords: Magnetic field intensity, reduction to equator, autogain control filter, baked clay bricks, Sungai Batu 


\section{INTRODUCTION}

Magnetic survey measures combined primary magnetic field intensity of the different components of the earth. The earth's magnetic field can be separated into three parts: the main field which is produced in the outer core and accounts for the very large regional variations in the field intensity and direction; the external field which is produced by electric currents of charged particles in the earth's ionosphere and the anomalous field which is induced in geological units; and utilities, archaeological remains and other forms of object buried in the earth's crust. The method provides a means for probing the earth's subsurface in a nondestructive manner, by taking advantage of contrast in magnetic susceptibility of subsurface materials. ${ }^{1,2}$ Techniques are now available to acquire magnetic data on land, at sea and in air..$^{3-7}$ Cost effectiveness and high resolution obtained in ground magnetic surveys, especially for small scale investigations, have made it a very attractive tool for mineral prospecting, ground water and structural studies. ${ }^{8-11}$

Various geophysical methods have been used previously to map possible locations of clay bricks in the study area. Resistivity method has been applied to map the area. ${ }^{12}$ Anomalies with relatively high resistivity values $(>3500 \Omega \mathrm{m})$ at depths of $<1 \mathrm{~m}$ were identified and interpreted as signatures of clay bricks. Because of the ambiguity involved in interpreting resistivity data and possible emergence of false anomalies, boreholes were recommended to validate the results. Other geophysical methods such as magnetic were also recommended to further investigate studied area. To address the ambiguity, ground magnetic data were acquired alongside resistivity profiles. ${ }^{13}$ High magnetic anomalies (30-180 nT) were identified and interpreted as signatures of buried archaeological featured such as the clay bricks, since clay is believed to be of high magnetic susceptibility relative to the surrounding sandy-clay materials. Pattern of the anomalies identified, however, has made it difficult to associate them with possible locations of the causative bodies.

Difficulty associated with interpretation of magnetic anomalies due to their dipolar nature is well known in geophysics. This property makes interpretation inaccurate as peaks of anomaly are skewed from centre of their magnetic sources. Also, remnant regional field anomalies in the residual field, even after regionalresidual separation, especially at locations with high background magnetic signal amplitude often dominates those in regions of low magnetic signal amplitude. This has consequences of losing useful anomalies for analysing the subsurface. To ameliorate these problems, a phase shift correction known as reduction to the equator (RTE) for areas closer to the equator (or reduction to pole for areas near the magnetic pole) is applied to shift the peaks of the anomaly almost exactly 
above the causative bodies. ${ }^{14,15}$ Similarly, automatic gain control (AGC) filter is used to enhance signal in regions of low magnetic variability and subdue signal in regions of high background magnetic field. This way, signals of all significant anomalies are equalised and thus treated evenly across the area. ${ }^{16}$

This study hierarchically combines RTE and AGC filters to analyse ground magnetic data acquired at Sungai Batu, Lembah Bujang, Kedah, Malaysia. The objective is to characterise and interpret magnetic signatures of buried structures in search for possible archaeological remains in area.

\section{EXPERIMENTAL}

\subsection{Study Area}

The study was carried out at part of Sungai Batu, Lembah Bujang, Kedah, Malaysia. Sungai Batu is located near Gurung Jerai and Sungai Merbok (Figure 1). ${ }^{17}$ The bedrock is sandstone, shell and mudstone. There exist a few small rivers and swamp at the eastern part of the area. The area is regarded as sedimentary, comprising of two soil types; sandy clay and fine sand. The sediments are believed to be transported from the river. The area has flat geomorphology, filled with rubber and palm trees.

\subsection{Data Acquisition and Analyses}

Ground magnetic field data were acquired using Geometrics G-856 proton precession type magnetometer and GPS navigation equipment along 17 profiles, spread at approximately $2 \mathrm{~m}$ interspacing (Figure 2). Each profile consists of 31 moving stations at $1 \mathrm{~m}$ minimum spacing, oriented in the west-east direction to form a $1 \mathrm{~m} \times 2 \mathrm{~m}$ grid. During the data acquisition, suitable base station was established at $50 \mathrm{~m}$ from the study area, to record readings at 1-min interval for diurnal correction and regional-residual separation. This was achieved by subtracting the base values from the measured grid values. The residual magnetic field intensity data were gridded using minimum curvature method, and plotted using Oasis Montaj software package. ${ }^{18}$ 


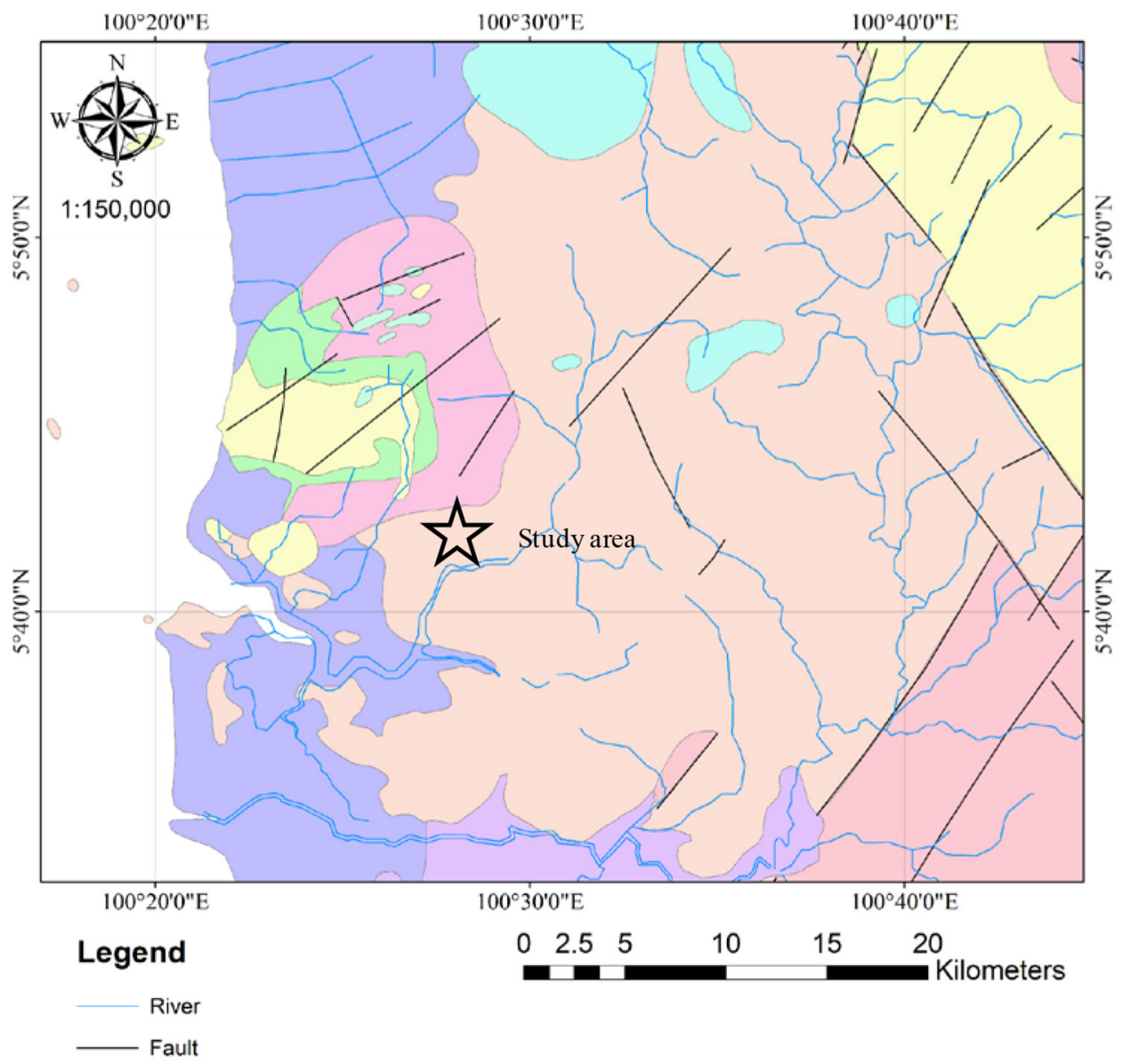

\section{LITHOLOGY}

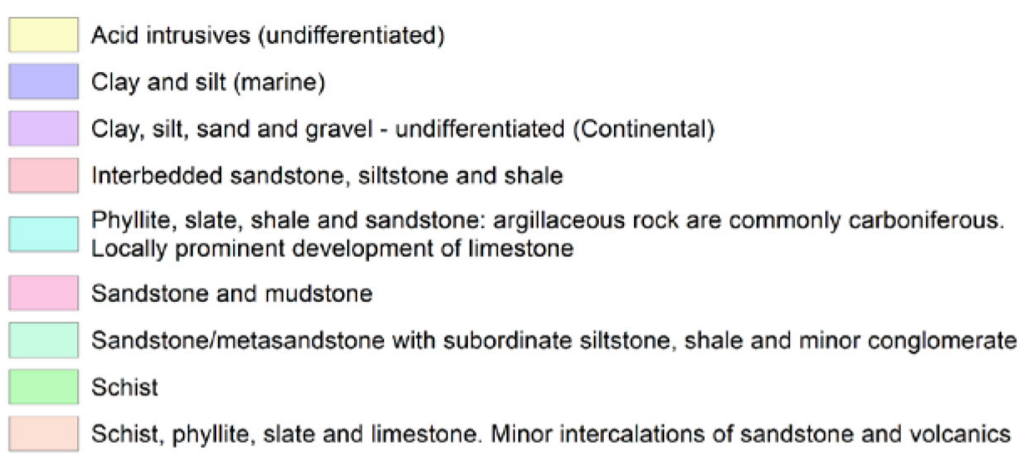

Figure 1: Geology map of the study area (full-coloured illustration available in digital version). 


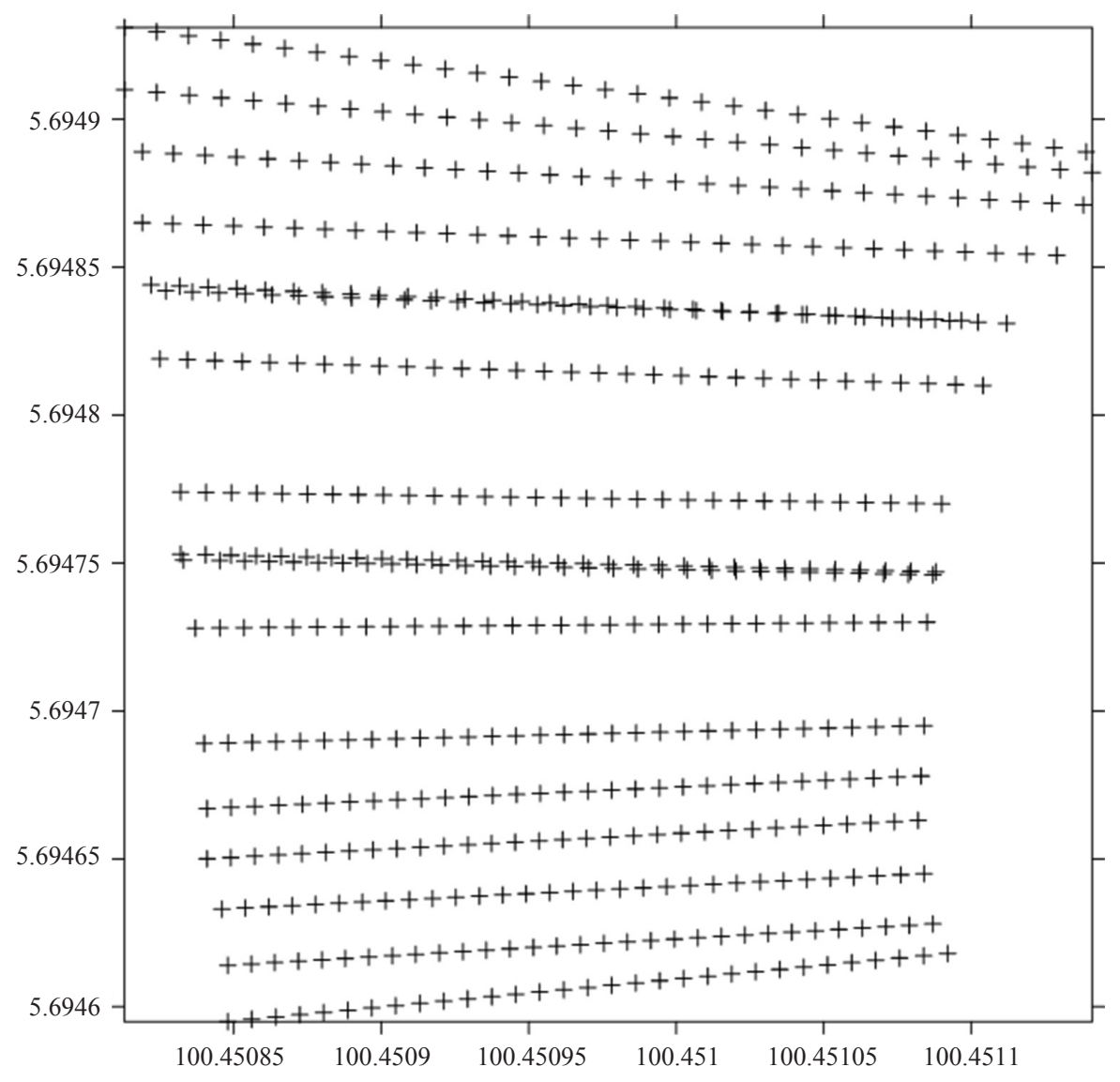

Figure 2: Survey layout.

The filtering started with RTE using Oasis Montaj at the first step, to place anomalies over their sources. RTE is used in low latitude regions to shift amplitudes of magnetic anomalies over their sources. An expression for RTE is given as:

$L(\theta)=\frac{\left[\sin I-i \cos I \cdot \cos (D-\theta)^{2}\right]\left[-\cos ^{2}(D-\theta)\right]}{\left[\sin ^{2} I_{a}+\cos ^{2} I_{a} \cos ^{2}(D-\theta)\right]\left[\sin ^{2} I+\cos ^{2} I \cos ^{2}(D-\theta)\right.}$ if $\left|I_{a}\right|<|I| . I_{a}=I$

where $I$ is the geomagnetic inclination, $I_{a}$ is the inclination for amplitude correction, $D$ is the geomagnetic declination, $\sin ^{2} I$ is the amplitude component while $\cos ^{2} I \cos ^{2}(D-\theta)$ is the phase component. This is a method of removing the dependence of magnetic data on the angle magnetic inclination. The filter converts magnetic data recorded at the inclined earth's magnetic field to what the data would look like if the inclination was zero. 
In the second step, AGC was applied using Oasis Montaj to boost amplitudes in regions with smooth anomalies, without sacrificing the long-wavelength information. The software was used to estimate gain with a sliding square filter window, centred on each grid node in turn. A maximum gain correction was specified to prevent the procedure from blowing up in regions of low signal. Inside the filter window centred at each position, a best-fit plane was calculated, which minimised the root-mean-square (RMS) misfit with the data. The average RMS difference between the data and plane values within the window is the local signal gain. Signal at the grid node in the centre of the window is the difference between the data value and the plane value at that position. The first pass over the grid determines the signal and gain for each position and records the largest (maximum) gain encountered. In the second pass, the signal at each position is multiplied by the ratio of maximum to local gain, but not exceeding the specified maximum correction. The gained signal is then added to the original background value to obtain the final signal value. ${ }^{16}$

Patterns of anomalies in the first and second steps filtering in relation to the original residual map produced were observed and interpreted.

\section{RESULTS AND DISCUSSION}

Figure 3 shows the residual magnetic field intensity at the study area. The residual magnetic field intensity values obtained after removing the regional field intensity values from the total magnetic field data are observed to be in the range of $-25 \mathrm{nT}$ to $177 \mathrm{nT}$. The values are classified as low $(<38 \mathrm{nT})$ and high magnetic (> $38 \mathrm{nT}$ ). Magnetic high anomaly features in the range of 62-117 nT and highlighted in red and pink colours, are predominant in the north-central, northeast and east-central parts of the area. They are interpreted as signatures of interbedded sandstone/mudstone materials, and/or highly magnetised shallow intrusions beneath the sediments. The magnetic low at the western part of the area is interpreted as sedimentary materials (clay and sand) transported from the rivers. This agrees with the interpretation of Saad et al. for resistivity anomalies and Nordiana et al. for resistivity and magnetic anomalies. ${ }^{12,13}$ From the figure, it is hard to deduce any clear anomaly pattern to indicate the baked clay bricks, which are believed to be also highly magnetic relative to their lacustrine sedimentary cover. ${ }^{18}$ However, their magnetic effects were obliterated by presence of anomalies of surrounding materials at the east and northern parts, which are generally more prominent and therefore portray higher magnetic appearance than the baked clay. Based on the findings of resistivity and magnetic surveys conducted in the area, the portions marked A, B and C on the figure are the regions of suspected baked clay bricks anomalies. ${ }^{12,13}$ 


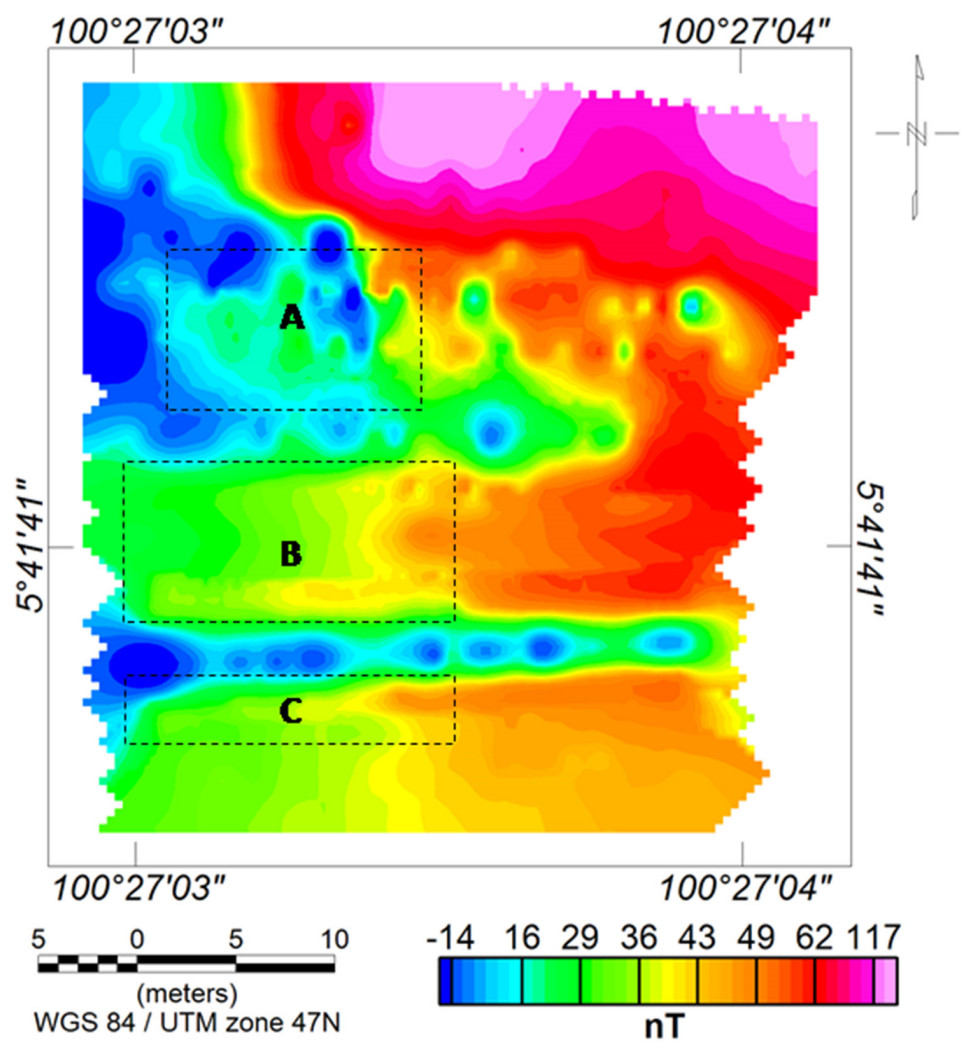

Figure 3: Residual magnetic field intensity map of the study area. Areas marked A, B and $\mathrm{C}$ are portions of suspected anomalies (full-coloured illustration available in the digital version).

The RTE residual magnetic field intensity map (Figure 4) shows a northward shift of the anomalies and a highlight of anomalies of intermediate magnetic intensity within zones B and C. The northward shift of the anomalies is clearly observed with residual anomalies of high intensity in the top northeastern part of the study area. It can be oberved from the figure that anomalies in the regions of interest are reoriented in a more refined manner than obtained in Figure 3. The adjustments made by RTE have now shifted the anomaly positions to supposedly conform with their causative materials, ${ }^{14,15}$ especially in regions B and C. In region A however, the anomalies are masked by presence of the high magnetic anomaly at the northeastern part of the area.

Figure 5 shows that on applying the AGC filter on the RTE residual magnetic field intensity grid, anomalies trending along east-west and northwest-southeast directions which were associated with the baked clay bricks are highlighted. 
Furthermore, similar anomalies of the same characteristics to the east of zone A, which were hitherto not observed in previous geophysical works in the area, are highlighted and interpreted to reflect high possibility of presence of near surface baked clay bricks beneath that area. ${ }^{12,13}$ In addition, anomalies associated with the baked clay bricks within zones $\mathrm{B}$ and $\mathrm{C}$ were greatly enhanced with their edges better defined and their propagation beneath the eastern part inferred. Generally, trend of the anomalies in these areas is along east-west direction. Similar anomalies were detected when resistivity method was applied to investigate the study area. ${ }^{12}$ The AGC filter was primarily used to boost the signals in regions of low magnetic variations, presumably masked by the high magnetic more prominent anomalies. The filter also removes the background component in the high magnetic variability regions that were ought not to have been completely removed from the regionalresidual separation. This way, all the signals across the study area were equalised and treated fairly. ${ }^{16}$

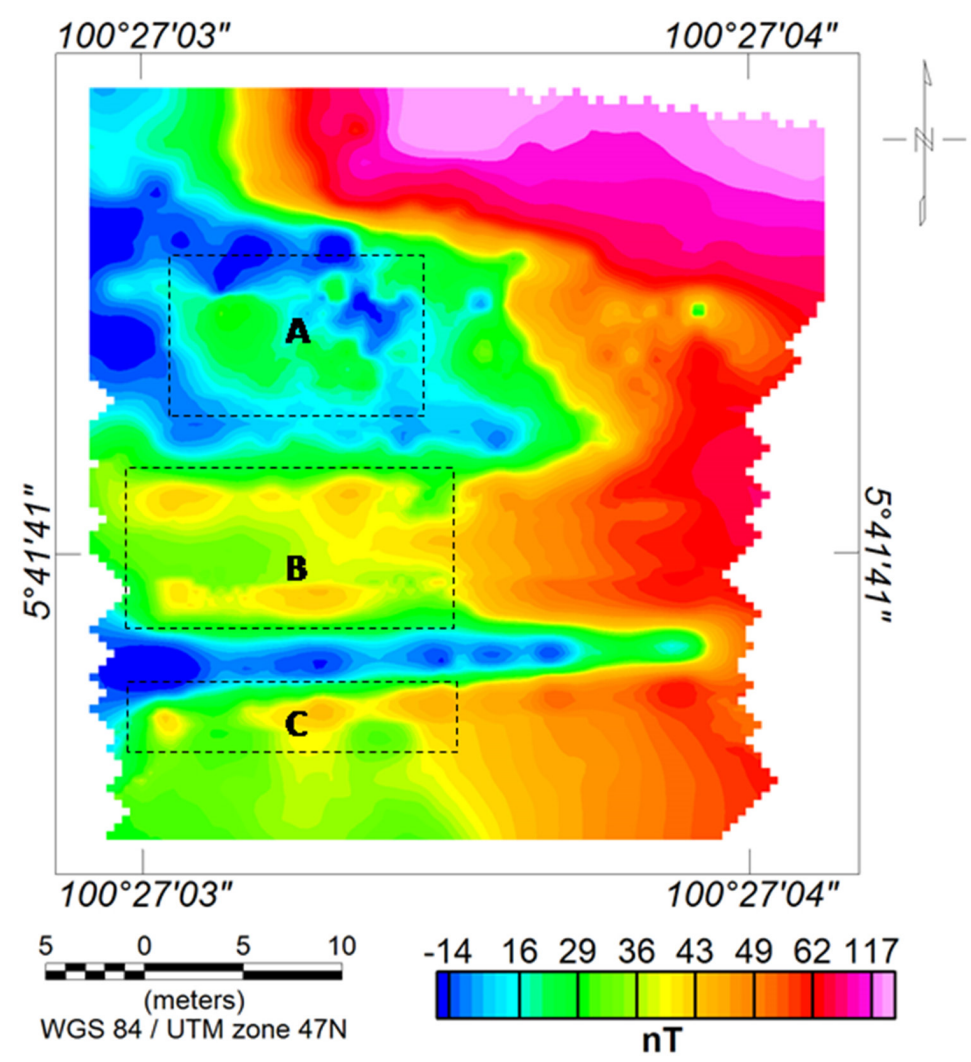

Figure 4: Residual magnetic field intensity map after reduction to equator. Areas marked $\mathrm{A}, \mathrm{B}$ and $\mathrm{C}$ are portions of suspected anomalies (full-coloured illustration available in the digital version). 


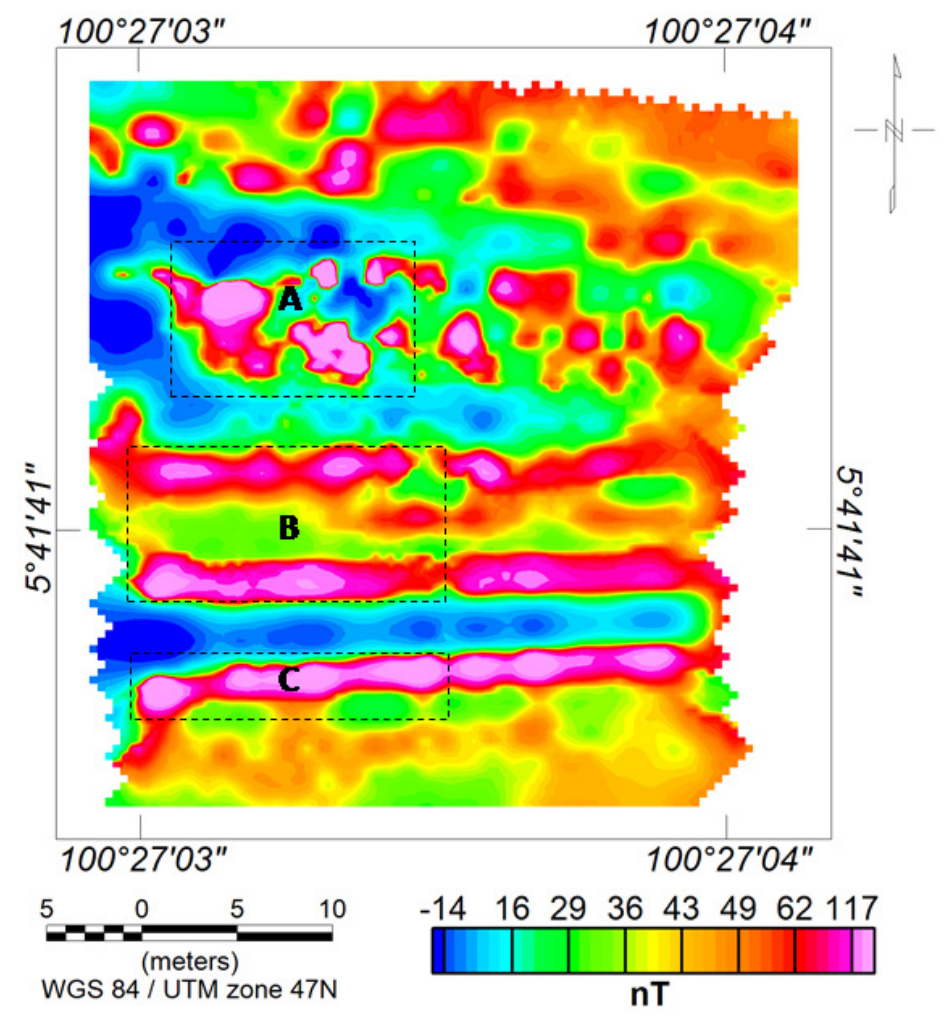

Figure 5: Two-step filtered image obtained from RTE-AGC. Areas marked A, B and C are portions of suspected anomalies (full-coloured illustration available in the digital version).

\section{CONCLUSION}

Analyses and interpretation of ground magnetic data acquired at Sungai Batu, Lembah Bujang, Kedah, Malaysia were conducted in search for archaeological remains, typically in the form of baked clay bricks. Magnetic field intensity data were acquired, corrected and analysed to produce the residual magnetic field intensity grid map. The residual field intensity values were obtained in the range of $-25 \mathrm{nT}$ to $177 \mathrm{nT}$. The values were generally classified in two main classes; low magnetic $(<38 \mathrm{nT})$, mostly obtained at the western part of the area and high magnetic ( $>38 \mathrm{nT})$, obtained at the eastern part. Post-processing of the grid using hierarchical combination of RTE and AGC filters refined the shape, location, orientation and extent of the anomalies of interest. The major anomalies, located in regions $\mathrm{B}$ and $\mathrm{C}$ were generally rod-like, trending in the west-east direction. Few other anomalies were also identified in region $\mathrm{A}$. 


\section{ACKNOWLEDGEMENTS}

The authors would like to thank Centre for Global Archaeological Research, Universiti Sains Malaysia for sponsoring the research and the Geophysics team, Universiti Sains Malaysia for their help with data acquisition.

\section{REFERENCES}

1. Muhammad, S. B. et al. (2014). Spectral analysis and estimation of depths to magnetic rocks below the Katsina area, Northern Nigerian basement complex. J. Phys., 3, 13-23.

2. Suleiman, T., Udensi, E. E. \& Muhammad, S. B. (2014). Analysis of aeromagnetic data across Kebbi State, Nigeria. Int. J. Mar. Atmos. Earth Sci., 2, 41-45.

3. Samuel, Y. M. et al. (2018). Integration of magnetic and geotechnical methods shallow subsurface soil characterization at Sungai Batu, Kedah, Malaysia. J. Phys., 995(012090), 1-7. https://doi.org/10.1088/1742-6596/995/1/012090

4. Yusoh, R. et al. (2018). Optimization of archaeological anomalies using GIS method for magnetic and resistivity study at Sungai Batu, Lembah Bujang, Kedah (Malaysia). J. Phys., 995(012072), 1-6. https://doi.org/10.1088/1742 $-6596 / 995 / 1 / 012072$

5. Yu, X. et al. (2017). Expansion of the South China sea basin: Constraints from magnetic anomaly stripes, sea floor topography, satellite gravity and submarine geothermics. Geosci. Front., 8, 151-162. https://doi.org/10.1016/j.gsf.2015.12.008

6. Muhammad, S. B. \& Saad, R. (2018). Regional structural architecture of part of northern Nigeria basement complex inferred from upward continuation of magnetic field intensity data. J. Phys., 1083(012057), 1-6. https://doi.org/10 $.1088 / 1742-6596 / 1083 / 1 / 012057$

7. Ajana, O. et al. (2014). Spectral depths estimate of subsurface structures in parts of Borno Basin, Northeastern Nigeria, using aeromagnetic data. J. Appl. Geol. Geophys., 2, 55-60.

8. Rabeh, T. (2016). Tracing the manganese ore accumulations in Sinai Peninsula, Egypt, using magnetic method. Environ. Earth Sci., 75, 1-12. https://doi.org/10 $.1007 / \mathrm{s} 12665-015-4966-6$

9. Joel, E. S. et al. (2016). Regional groundwater studies using aeromagnetic technique. Paper presentated at AAPG/SEG International Conference \& Exhibition, Cancun, Mexico, 6-9 September.

10. Muhammad, S. B. et al. (2018). Internal architecture of meteorite impact crater at Bukit Bunuh, Lenggong - Perak, Malaysia inferred from upward continuation of magnetic field intensity data. J. Phys., 995(012092), 1-7. https://doi.org/10 $.1088 / 1742-6596 / 995 / 1 / 012092$

11. Ismail, N. E. H. et al. (2018). Analyses of magnetic and gravity data in search for meteorite impact crater at Bukit Bunuh, Lenggong - Perak, Malaysia. J. Phys. Sci., 29(3), 109-119. https://doi.org/10.21315/jps2018.29.3.9 
12. Saad, R., Nordiana, M. M. \& Saidin, M. (2014). Resistivity studies of archaeological anomaly at Sungai Batu, Lembah Bujang, Kedah (Malaysia). Electron. J. Geotech. Eng., 19, 2589-2596.

13. Nordiana, M. M. et al. (2014). Archaeological prospection at Lembah Bujang, Kedah (Malaysia) using resistivity and magnetic method. Electron. J. Geotech. Eng., 19, 4371-4779.

14. Rajagopalan, S. (2003). Analytic signal vs. reduction to pole: Solutions for low magnetic latitudes. Explor. Geophys., 34(4), 257-262. https://doi.org/10.1071/ EG03257

15. Anudu, G. K., Stephen, R. A. \& Macdonald, D. I. M. (2014). Using high-resolution aeromagnetic data to recognise and map intra-sedimentary volcanic rocks and geological structures across the Cretaceous middle Benue Trough, Nigeria. J. Afr. Earth Sci., 99, 625-636. https://doi.org/10.1016/j.jafrearsci.2014.02.017

16. Dentith, M. (1995). Textural filtering of aeromagnetic data. Explor. Geophys., 26(3), 209-214. https://doi.org/10.1071/EG995209

17. Wheatley, P. (1961). The Golden Khersonese: Studies in the historical geography of the Malay Peninsula before AD 1500. Kuala Lumpur: University of Malaya Press.

18. Briggs, I. C. (1974). Machine contouring using minimum curvature. Geophys., 39, 39-48. https://doi.org/10.1190/1.1440410 